УДК 159.9

DOI: $10.18384 / 2310-7219-2015-3-46-52$

\author{
Виноградова А.B. \\ Московский педагогический государственный университет \\ ПРАКТИКО-ЗНАЧИМЫЕ УСТНЫЕ УПРАЖНЕНИЯ \\ НА УРОКАХ ГЕОМЕТРИИ КАК ФАКТОР САМОРЕАЛИЗАЦИИ \\ ОБУЧАЮЩИХСЯ В КОММУНИКАТИВНОЙ ДЕЯТЕЛЬНОСТИ
}

Аннотация. В данной статье представлен анализ понятий «коммуникативная деятельность», «самореализация», «устные упражнения»; рассматриваются направления организации устной работы на уроках геометрии, нацеленные на фрормирование потребности самореализации обучающихся в коммуникативной деятельности. В работе приводится классификация устных упражнений, в которой учтены такие факторы, как профиль обучения, уровень (базовый или углубленный) изучения дисциплины, характер работы с обучающимися (самостоятельная работа в группе или совместная работа учеников с учителем) и т.д.

Ключевые слова: обучение учащихся на уроках геометрии, школьное математическое образование, коммуникативная деятельность, устная работа, самореализация.

\author{
A. Vinogradova \\ Moscow State Pedagogical University
}

\title{
PRACTICE-RELEVANT ORAL EXERCISES AT GEOMETRY LESSONS AS A FACTOR OF SENIORS' SELF-REALIZATION IN COMMUNICATIVE ACTIVITY
}

Abstract. This article analyzes the concepts of "communicative activity", "self-actualization", "oral exercises". The main lines of the organization of oral work at the lessons of geometry, aimed at developing students' need of self-realization in the process of communicative activities are considered. The classification of oral exercises is given which takes into account such factors as the teaching profile, the level (basic or advanced) of studying the subject, the type of teaching (independent work in a group or teacher and students collaboration) etc.

Key words: teaching students at the lessons of geometry, school education in mathematics, communicative activities, oral work, self-realization.

Целью отечественного школьного образования на современном этапе является создание таких условий для самореализации обучающегося, при которых учебный процесс способствовал бы становлению у школьника готовности быть творцом собственной жизнедеятельности на всех этапах об-

(с) Виноградова А.В., 2015. разовательного и будущего профессионального пути. Данная цель должна быть реализована, в том числе, при обучении математике.

С введением ФГОС основного и среднего (полного) общего образования возникла необходимость выхода образования из устоявшейся модели знаний, умений и навыков, так как на 
всех ступенях обучающимся необходимо большее: потребность самореализации в будущей профессиональной и коммуникативной деятельности, отвечающая требованиям общества, исходящая из личностных качеств, которые присваиваются в процессе учебно-познавательной деятельности, в том числе коммуникативной. Современное общество нуждается в мобильной, конкурентоспособной, креативно и нравственно мыслящей личности, эффективно координирующей свою профессиональную деятельность в тесном коммуникативном взаимодействии с членами данного общества.

В научно-методической литературе коммуникативная деятельность рассматривается:

- как целенаправленное диалогическое взаимодействие всех субъектов обучения, выражающееся в переносе объективных коммуникативных умений в субъективные практические навыки и умения обучающихся [6];

- $\quad$ как процесс формирования коммуникативной компетентности [1;4].

Обучающиеся, участвуя в коммуникативной деятельности, приобретают опыт, лежащий в основе коммуникативной успешности, которая определяется как результат положительного опыта учебной коммуникативной деятельности, проявляющегося в стремлении учащихся включиться в учебное общение на своём уровне развития, обученности, воспитанности.

Школьники имеют обширные возможности заниматься самореализацией в коммуникативной деятельности при проведении устной работы на уроках геометрии, так как устные упражнения и задачи всецело направлены на формирование его проблемно-поиско- вой активности, развитие интеллектуального потенциала, самовыражение, развитие его языковой культуры, профессиональное самоопределение.

Естественно, что не каждое, полученное на уроках геометрии умение сохраняется в памяти школьника. Однако навсегда сохраняется привычка анализировать и рассуждать, остаётся навык объяснять и аргументировать те или иные положения, фиксируется умение искать и находить оптимальные и творческие способы разрешения возникающих в жизни проблем.

Следовательно, актуальной становится проблема такой организации процесса обучения математике (в частности, геометрии), которая способствовала бы будущей профессиональной самореализации и социальному становлению обучающихся школы путём приобретения фундаментальных математических знаний учащимися, накопления коммуникативного опыта и социальных умений.

Анализ содержания понятия «самореализация» показал, что самореализация - одна из важнейших потребностей в жизни любого индивида [8], характеризующаяся, как правило, приобретёнными предметными (фундаментальными) умениями в той или иной области жизнедеятельности и жизненными (прикладными) навыками их реализации. Потребность самореализации формируется на основе становления предметных интеллектуальных умений и практической реализации различных видов учебнопознавательной деятельности, прогнозирования результатов деятельности, рефлексии.

Когда обучающемуся приходится оперировать геометрическими тер- 
минами, объясняя те или иные явления и процессы, находясь в поиске взаимосвязи понятий и суждений, он решает задачу познания [11]. В связи с этим учебный материал с позиции дидактики характеризуется как оптимальная система познавательных задач, необходимых для анализа связей различных его сторон. Таким образом, учебный материал нужно подавать через систему учебных ситуаций, в содержании которых присутствуют предметные знания и практические границы их использования. Задачи, как правило, формулируются в виде общих и частных проблем и вопросов, предназначенных выявить главную идею, признаки и свойства, особенности применения в практике.

Так, основными методическими средствами формирования потребности самореализации обучающихся в условиях коммуникативной деятельности на уроках геометрии являются практикозначимые устные упражнения.

Различные педагоги предлагали и предлагают разные классификации упражнений, опираясь в своих исследованиях на особенности того или иного учебного предмета, возраст обучаемых, дидактические цели и организационно-педагогические условия процесса обучения. Перечислим позиции некоторых из них.

И.Г. Липатникова на основе познавательных потребностей, мотивации и интереса обучающихся подразделяет устные упражнения на четыре категории: 1) упражнения, требующие воспроизведения данных; 2) требующие простых мыслительных операций с данными; 3) требующие сложных мыслительных операций с данными; 4) требующие творческого мышления [5].
И.Ф. Харламов считает, что в содержание упражнений целесообразно включать проблемные задания, которые требовали бы от обучаемых вдумчивого подхода к получению-применению знаний [12].

П.А. Батчаева предлагает собственную классификацию устных упражнений, опираясь, прежде всего, на тренировку тех или иных знаний и умений: тренировочные; активирующие мыслительную деятельность; требующие развития творчества и изобретательности; воспитывающие правильную речь; пространственное мышление; подчеркивающие связь теоретического материала с прикладным применением знаний [2].

Таким образом, приведённые выше классификации строятся на основе либо содержательных, либо деятельностных компонентах учебного процесса.

По нашему мнению, устные упражнения, являясь подсистемой общей системы упражнений, с одной стороны, должны включать в себя те же характеристики, что и обобщающий термин «упражнения»; с другой стороны, при составлении классификации устных упражнений и определении методики их использования на уроках геометрии в старших классах необходимо учитывать следующие факторы: в каких профильных классах проводится обучение (естественнонаучных, гуманитарных и пр.); базовый или углубленный уровень изучения геометрии предлагается обучающимся; каков будет характер деятельности с обучающимися при использовании устных упражнений (самостоятельная работа в группе или совместная работа учеников с учителем); какие дидактиче- 
Классификация устных упражнений

\begin{tabular}{|c|c|c|}
\hline \multirow{4}{*}{ Профиль обучения } & Гуманитарный & $\begin{array}{l}\text { Содержание упражнений формируется } \\
\text { в зависимости от гуманитарного профи- } \\
\text { ля обучения в старших классах школы и } \\
\text { носит межпредметный облегчённый ха- } \\
\text { рактер }\end{array}$ \\
\hline & Естественноматематический & $\begin{array}{l}\text { Содержание упражнений носит пре- } \\
\text { имущественно предметный (геометриче- } \\
\text { ский) характер, включены методологиче- } \\
\text { ские знания }\end{array}$ \\
\hline & Технологический & $\begin{array}{l}\text { Содержание вопросов включает различ- } \\
\text { ные связи с различными областями жиз- } \\
\text { недеятельности человека: строительство, } \\
\text { архитектура, дизайн, география }\end{array}$ \\
\hline & Социально-экономический & $\begin{array}{l}\text { Содержание вопросов включает знания } \\
\text { из области экономики }\end{array}$ \\
\hline
\end{tabular}

ские цели ставит перед собой педагог, использующий для организации коммуникативной деятельности устные (вспомогательные, тренировочные, развивающие) упражнения; дивергентный или конвергентный характер выполнения упражнений будет выбираться при изучении того или иного раздела геометрии и при формировании тех или иных коммуникативных качеств обучаемых.

Использование практико-значимых устных упражнений при организации коммуникативной деятельности обучающихся на уроках геометрии является оптимальным средством развития познавательного интереса. Примерами упражнений, направленных на выработку умений осмысливать жизненную ситуацию, применять полученные знания на практике, могут служить известные задачи на определение ширины реки, высоты дерева и т.д. Осуществление связи теории с практикой особенно важно в процессе обучения геометрии, так как через привлечение реальных объектов появляется возможность подчинить обучение жизненным интересам, подготовить учащихся к самостоятельной трудовой жизни. «Изучение математики без должной связи с жизнью, без наглядности, - говорил А.И. Маркушевич, - мешает развитию логического мышления, снижает уровень математической подготовки молодежи» [7, с. 68]. Обращение к примерам из жизни, окружающей обстановки способствует возникновению значимого учебно-познавательного мотива, более глубокому усвоению теоретических положений, формирует умения применять математические знания на практике. Таким образом, устные упражнения с практико-значимой направленностью являются эффективным и часто незаменимым средством усвоения курса математики, средством формирования нужной мотивации, интереса к изучению математики. Приведём примеры некоторых практико-значимых устных упражнений в зависимости от профиля обучения: гуманитарный характер содержания, естественноматематический, технологический, социально-экономический (табл. 1). 
Одним из способов организации коммуникативной деятельности на уроках математики является устная работа. Это необходимый элемент на уроках, так как в геометрии устные упражнения способствуют развитию у учащихся пространственных представлений и пространственного воображения. Подобного рода вопросы позволяют с минимальной затратой времени раскрыть сущность изучаемого понятия, выделить его характерные признаки. Важную роль устная работа играет при организации повторения, особенно в старших классах, так как намного чаще и в большем объёме привлекаются ранее полученные знания. Содержание устных вопросов зависит от многих факторов: определения целей урока; учётом уровня подготовки и возраста учащихся и т.д. Рассмотрим примеры устных упражнений в зависимости от профиля обучения.

При выборе устных упражнений были использованы следующие источники $[3 ; 9 ; 10]$ :

Примеры устных упражнений для учащихся гуманитарного профиля

1. Что означают термины «призма», «куб», «параллелепипед», «пирамида»?

2. Приведите примеры некоторых строчек из песен, в которых упоминаются пирамиды.

3. В каких стихотворениях упоминаются пирамиды? Какие существуют версии по поводу возникновения пирамид?

4. Какие знаменитые архитектурные сооружения имеют форму пирамид?

5. А.С. Пушкин писал:

У лукоморья - дуб зелёный, Златая цепь на дубе том.

И днём и ночью кот учёный
Все ходит по цепи кругом.

Верно ли, что «кот учёный» при таком движении описывает окружность?

Упражнения для учашихся технологического профиля

1. Чтобы проверить горизонтальность планшета мензулы (рис. 1), устанавливают уровень в двух направлениях. Объясните, почему так поступают. (Комментарии: мензула - полевой чертёжный столик, состоящий из планшета, штатива и скрепляющей их подставке; планшет - доска с натянутой на ней бумагой, на которую наносится план местности при топографической съёмке.)

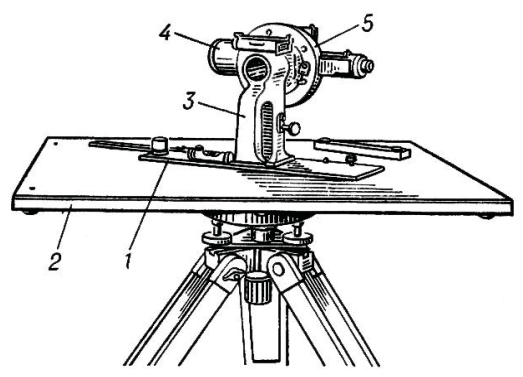

Puc. 1

2. Как проверить с помощью чертёжного треугольника, что стержень поршня цилиндра перпендикулярен плоскости поверхности поршня?

3. Чтобы построить навес, параллельный поверхности земли, поступают следующим образом: ставят несколько столбов одинаковой длины, перпендикулярных поверхности земли и располагающихся в разных плоскостях, на них кладут навес. Почему он будет параллелен поверхности земли?

4. Для установки радиомачты к ней на высоте 4 м прикреплены три оттяжки, привязанные к кольям, вбитым в землю на расстоянии 3 м от основания мачты. Найдите длину каждой оттяжки. 
5. Громоотвод защищает от молнии все предметы, расположенные от его основания не далее его двойной высоты. Требуется установить громоотвод на крыше здания, имеющей в плане форму прямоугольника с диагональю 20 м. Найдите его наименьшую высоту.

Устные упражнения практического содержания представляют собой в большинстве случаев вопросы, в которых требуется дать геометрическое обоснование факту, наблюдаемому в практической жизни, или указать, как следует поступить в определённой практической ситуации, опираясь на знания соответствующих геометрических предложений. Подобного рода вопросы должны быть включены в содержание устной работы для учащихся технологического профиля.

Упражнения для учащихся естественно-математического пробиля

1. «Крышка коробки закреплена на двух шарнирах $C$ и $D$. Чтобы оставить коробку открытой, надо подпереть крышку в некоторой точке $A$ планкой $A B$ (рис. 2)». Дайте геометрическое обоснование этому факту.

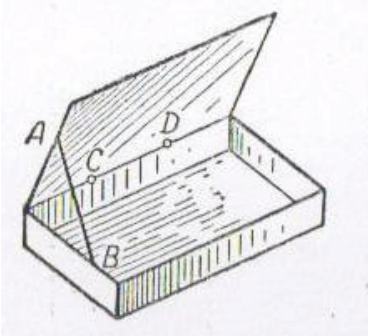

Рис. 2

2. Палатка имеет вид, изображённый на рисунке 3. Длина её 4 м, ширина 2 м и высота 2 м. Каков объём этой палатки? Сколько квадратных метров парусины потребовалось для её изготовления?

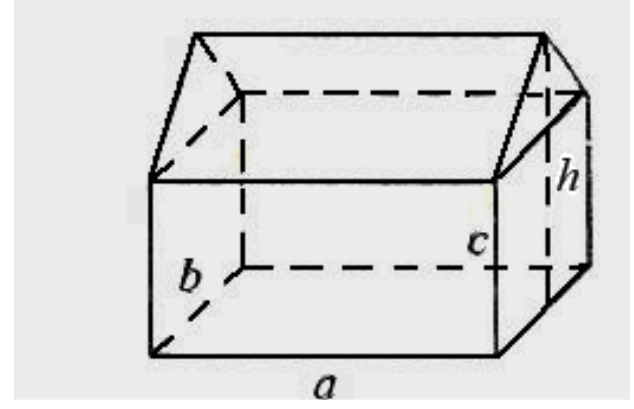

Puc. 3

3. Какой объём краски потребуется, чтобы окрасить поверхность шара радиусом 1 м слоем краски в 0,5 мм? Ответ дайте в кубических дециметрах.

(Примите $\pi \approx 3$.)

Организация устной работы на уроках геометрии имеет свою специфику, которая определяется организационно-содержательной подготовкой к коммуникативной деятельности, включающей в себя конкретизацию познавательных целей и задач и проектирование методики устной работы. Методика включает в себя, помимо общей характеристики устной работы, этапы и содержание коммуникативной деятельности обучающихся и педагога, обусловленные познавательными целями и предметной тематикой.

Коммуникативная деятельность в процессе устной работы позволяет обучающимся реализовать не только свои предметные умения, но и усовершенствовать недостаточно развитые коммуникативные взаимодействия с педагогом и одноклассниками. Разнообразные теоретические и практические методы получения и обработки предметных знаний по геометрии, виды умений, формирующих потребность самореализации личности 
обучающегося в коммуникативной деятельности, приобщение обучающихся к познанию исторических аспектов и ведущих идей развития геометрии всё это имеющие принципиальное значение средства не только самореализации обучающихся, но и формирования интереса к предмету геометрия, к процессу познания.

Результатом становления потребности самореализации в процессе коммуникативной деятельности при изучении геометрии является, кроме всего прочего, готовность и способность личности обучающегося к самообразованию и самовоспитанию. Отсюда следует, что обучающемуся школы необходимо координировать собственную коммуникативную деятельность при изучении геометрии с помощью навыков, формирующих потребность самореализации.

Таким образом, направления работы учителя в вопросах формирования потребности самореализации обучающихся школы в коммуникативной, а также будущей профессиональной и общественно-полезной деятельности, в полной мере соответствуют целям актуального школьного математического образования: организация коммуникативной деятельности на уроках геометрии как средства самореализации обучающихся; педагогическая поддержка учащихся в вопросах их будущей социализации и самореализации; формирование у школьников математической культуры и готовности к самообучению; становление способности к регулированию собственной учебно-познавательной и коммуникативной деятельности. Следовательно, разработка технологии формирования потребности самореализации обуча- ющихся школы средствами предмета «Геометрия» в условиях коммуникативной деятельности обучающихся школы актуальна.

\section{ЛИТЕРАТУРА:}

1. Андреева Г.М. Социальная психология. M., 1996. 384 c.

2. Батчаева П.А. Устные упражнения как одно из средств формирования математической культуры учащихся V-IX классов : дис. ... канд. пед. наук. Карачаевск, 2010. 198 с.

3. Виноградова А.В. Устные упражнения по стереометрии. М., 2014. 130 с.

4. Жуков Ю.М., Петровская Л.А., Растянников П.В. Диагностика и развитие компетентности в общении. М., 1990. $104 \mathrm{c}$.

5. Липатникова И.Г. Устные упражнения в системе развивающего обучения математике в начальной школе : дис. ... канд. пед. наук. Екатеринбург, 1999. $180 \mathrm{c}$.

6. Ломов Б.Ф. Методологические и теоретические проблемы психологии. М., 1999. $350 \mathrm{c}$.

7. Маркушевич А.И. Об очередных задачах преподавания математики в школе // Математика в школе. 1962. № 2. C. 67-69.

8. Маслоу А. Мотивация и личность. / Пер. А.М. Татлыбаевой. СПб., 1999. $478 \mathrm{c}$.

9. Смирнова И.М., Смирнов В.А. Геометрические задачи с практическим содержанием. М., 2010. 136 с.

10. Смирнова И.М., Смирнов В.А. Устные упражнения по геометрии. 10-11 классы : Учеб. пособие для учащихся общеобразовательных учреждений. М., 2010. 223 c.

11. Фридман Л.М. Теоретические основы методики обучения математике. 3-е изд. М., 2009. 248 с.

12. Харламов И.Ф. Как активизировать учение школьников // Дидактические очерки. Минск, 1975. 208 с. 